Provided for non-commercial research and education use. Not for reproduction, distribution or commercial use.

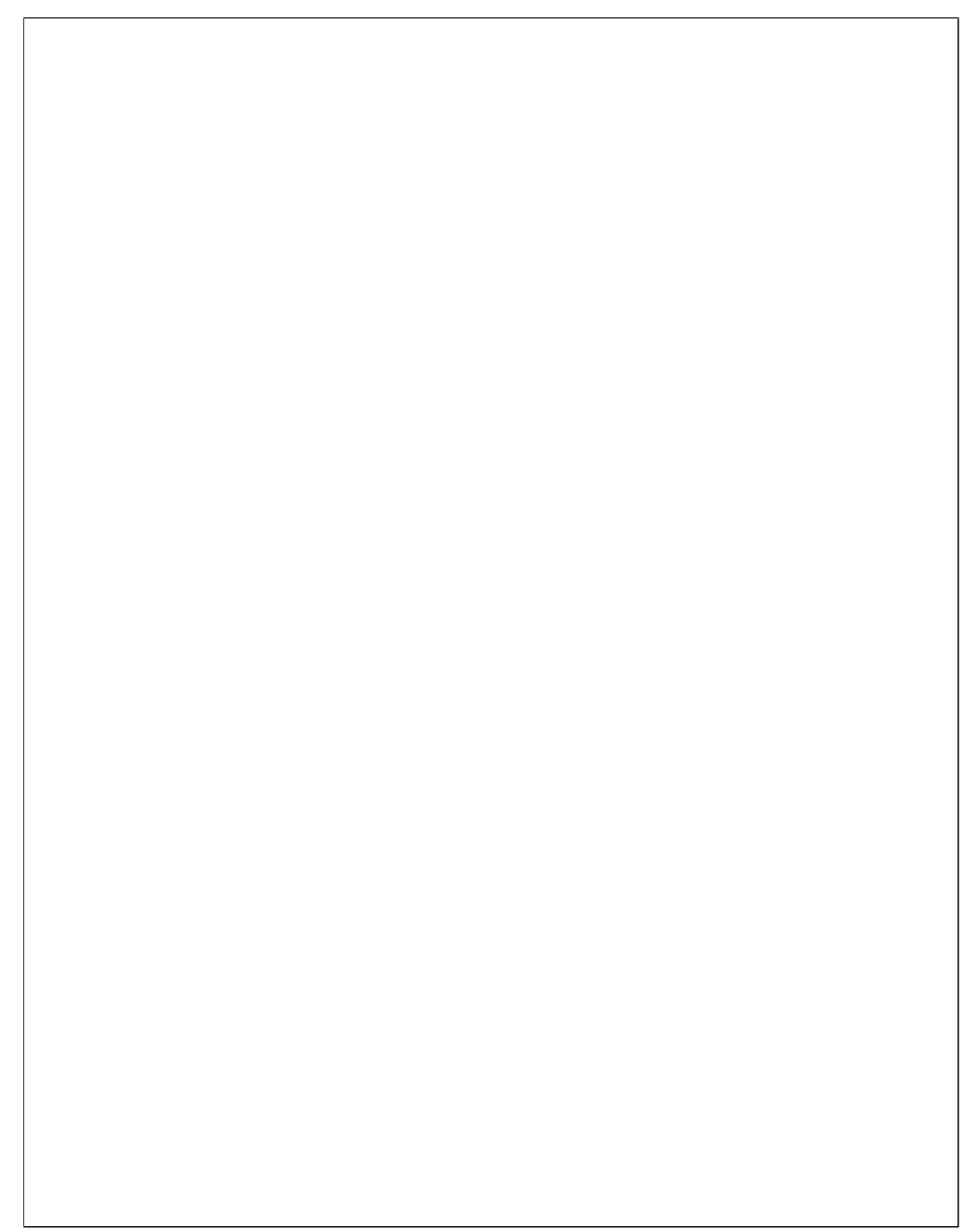

This article appeared in a journal published by Elsevier. The attached copy is furnished to the author for internal non-commercial research and education use, including for instruction at the authors institution and sharing with colleagues.

Other uses, including reproduction and distribution, or selling or licensing copies, or posting to personal, institutional or third party websites are prohibited.

In most cases authors are permitted to post their version of the article (e.g. in Word or Tex form) to their personal website or institutional repository. Authors requiring further information regarding Elsevier's archiving and manuscript policies are encouraged to visit:

http://www.elsevier.com/copyright 
Original Article

\title{
Prevalence of overweight in preschool children using the new WHO growth standards
}

\author{
Mohammad I. El Mouzan ${ }^{\mathrm{a}, *}$, Peter J. Foster ${ }^{\mathrm{b}}$, Abdullah S. Al Herbish ${ }^{\mathrm{a}}$, Abdullah A. Al Salloum ${ }^{\mathrm{a}}$, \\ Ahmad A. Al Omar ${ }^{c}$, Mansour M. Qurachi ${ }^{d}$, Tatjana Kecojevic ${ }^{\text {b }}$ \\ a Department of Pediatrics, King Saud University, P.O. Box 2925, Riyadh 11461, Saudi Arabia \\ ${ }^{\mathrm{b}}$ School of Mathematics, Manchester University, United Kingdom \\ 'The Children's Hospital, King Saud Medical Complex, Al yamama Hospital, Riyadh, Saudi Arabia \\ ${ }^{\mathrm{d}}$ Department of Pediatrics, Al yamama Hospital, Riyadh, Saudi Arabia
}

\section{A R T I C L E I N F O}

\section{Article history:}

Received 4 August 2009

Accepted 25 October 2009

\section{Keywords:}

Overweight prevalence

Saudi children

WHO reference

\begin{abstract}
S U M M A R Y
Background $\mathcal{E}$ Objective: Limited data are available on the prevalence of overweight in infants and children using the new WHO reference. Therefore, the objective of this study was to establish the prevalence of overweight in Saudi preschool children using the 2006 WHO child growth standards in comparison with the $2000 \mathrm{CDC}$ reference in order to suggest the most suitable reference.

Subjects and Methods: the data set of the 2005 Saudi reference was used to calculate the BMI for age in children below 60 months of age. The prevalence of overweight was calculated based on the two references using the WHO cutoffs (weight for height or BMI for age above +2 standard deviation score). A lower cutoff for excess weight, BMI for age $>+1$ SDS (equivalent CDC cut off for overweight) was also used. All calculations were performed using the WHO and CDC software as appropriate. Chisquare test was used to compare proportions and a $p$-value $<0.05$ was considered significant.

Results: There were 15554 children from birth to 60 months of age, in which the prevalence of BMI $>+2$ SDS (WHO cutoff for overweight) using the WHO standards was $6 \%$. Using the WHO and CDC reference, the prevalence of overweight by WHO cut off in the age group 24-60 months was 5\% and 5.8\% respectively $(p=0.100)$. Prevalence values using lower cut off for BMI for age $>+1$ SDS were $15.7 \%$ and $12.2 \%$ based on the WHO and CDC references respectively $(p=0.001)$. Conclusions: the prevalence of BMI $>+2$ SDS (overweight by WHO definition) in Saudi infants and young children is intermediately high, calling for preventive measures to prevent further increases described in other countries. The WHO child growth standards appear to be a more suitable reference for the surveillance of overweight in preschool children. However, this assumption needs confirmation by further studies on the relationship between cutoffs and health outcome.
\end{abstract}

(C) 2009 European Society for Clinical Nutrition and Metabolism. Published by Elsevier Ltd. All rights reserved.

\section{Introduction}

In almost all reports from different parts of the world, a high prevalence of overweight and obesity in children was documented. For example, in the United States of America (USA) the prevalence of BMI $>95$ th percentile (cutoff for obesity) in $1999-2000$ was $15.5 \%$ among 12 - through 19 -year-olds, $15.3 \%$ among 6 - through 11 -yearolds, and $10.4 \%$ among 2 - through 5 -year-olds, compared with $10.5 \%$, $11.3 \%$, and $7.2 \%$, respectively, in $1988-1994 .{ }^{1}$ Similarly, reports from

\footnotetext{
* Corresponding author. Department of Pediatrics, King Saud University, P.O. Box 2925, Riyadh 11461, Saudi Arabia. Tel.: +966 1467 0807; fax: +966 14679463.

E-mail address: drmouzan@gmail.com (M.I. El Mouzan).
}

the United Kingdom (UK) indicated increased prevalence of BMI $>95$ th percentile (obesity) in 11-15 year-olds from $17 \%$ in 1996 to $25 \%$ in $2004 .^{2}$ Reports from developing countries show disparity in the prevalence of overweight and obesity. High prevalence, similar to developed countries, has been reported from transitional countries like Brazil, ${ }^{3}$ United Arab Emirates, ${ }^{4}$ and Saudi Arabia; ${ }^{5}$ whereas low prevalence of overweight (4.94\% in 2003 and $6.67 \%$ in 2005) has been reported from India ${ }^{6}$ and a prevalence of $6.2 \%$ and $1.8 \%$ for overweight and obesity in 2002-2003 in schoolchildren from Yemen. $^{7}$

Most above-mentioned reports involve schoolchildren and adolescents and information on the prevalence of overweight and obesity in preschool children is scarce worldwide and mostly based on older references such as National Center for Health Statistics 
Table 1

Prevalence of BMI $>+2$ SDS in Saudi children 0-60 months using the WHO child growth standards.

\begin{tabular}{|c|c|c|c|}
\hline \multirow[t]{2}{*}{ Age (months) } & \multicolumn{3}{|c|}{ No. of children (\%) } \\
\hline & Boys & Girls & Combined \\
\hline $0-5$ & $3022(3.4)$ & $2845(3.8)$ & $5867(3.6)$ \\
\hline $6-11$ & $1304(9.3)$ & $1290(8.6)$ & $2594(8.9)$ \\
\hline $12-23$ & $1278(9.9)$ & $1221(11.4)$ & $2499(10.6)$ \\
\hline $24-35$ & $696(7.2)$ & 727 (6.1) & $1423(6.6)$ \\
\hline $36-47$ & $714(5.2)$ & $784(5.2)$ & $1498(5.2)$ \\
\hline $48-60$ & $844(3.9)$ & $829(2.5)$ & $1673(3.2)$ \\
\hline $0-60$ & $7858(6.0)$ & $7696(6.0)^{\mathrm{a}}$ & $15554(6.0)$ \\
\hline
\end{tabular}

$(\mathrm{NCHS}),{ }^{8}$ the Center for Disease Control and Prevention $(\mathrm{CDC})^{2}$ or on extrapolation from the International Task Obesity Force (ITOF) cut offs in adults. ${ }^{9}$ All these references do not include BMI below 2 years of age. The recent publication of the World Health Organization (WHO) child growth standards (WHO reference), which includes a BMI reference from birth to 60 months, ${ }^{10}$ provided a new tool for the assessment of prevalence of overweight in infancy and early childhood. The objectives of this report are to establish the prevalence of overweight in a preschool Middle-Eastern population from birth to 60 months of age using the WHO reference and to provide a comparison with the 2000 CDC reference for the available age group (24-60 months) in an attempt to identify the most suitable reference for early detection of excess weight in infants and young children.

\section{Subjects and methods}

The prevalence of overweight in Saudi preschool children (birth to 60 months) was calculated from the data set collected for the 2005 growth charts for Saudi children and adolescent survey (Saudi reference). The design and methodology of this study have been reported in details elsewhere. ${ }^{11}$ Briefly, the study sample was crosssectional, selected by multistage probability sampling procedure from a stratified listing based on the population census in the Kingdom of Saudi Arabia. Accordingly, the sample is representative of all the socioeconomic strata and consists of a majority of children with combined breast and formula milk feedings. Data collection was made by house-to-house visits where a survey questionnaire, clinical examination and body measurements were completed by primary care physicians and nurses. Weight, length and height measurements were performed by trained physicians and nurses. In children less than 2 years, weight was measured in the supine position on a sliding scale and length was measured in the supine position as well, whereas children above 2 years of age were weighed and their height was measured in the upright position according to standard recommendations. ${ }^{12}$ For both age groups body measurements were performed by 2 members of the field team. Intra- and inter-observer variability were checked once in every 100 measurements. Body mass index (BMI) was calculated according to the formula (weight/height ${ }^{2}$ ). Percentiles and $z$-scores of BMI for age were constructed and smoothed using the LMS Methodology. ${ }^{13-15}$ The prevalence of overweight was calculated based on the two newest references (the 2006 WHO child growth standards and the $2000 \mathrm{CDC}$ reference). The prevalence of overweight was defined according to the WHO cutoffs for this age group as the proportion of children whose BMI was above +2 standard deviation score (SDS). Another cutoff for excess weight, BMI for age $>+1$ SDS, similar to the BMI $>85$ th percentile (CDC cut off for overweight), was used to investigate the difference in prevalence between the two references at lower cut offs used by other references. All calculations were performed using the WHO and CDC software as appropriate. ${ }^{16,17}$ Chi-square test was used to compare proportions and a $p$-value $<0.05$ was considered significant.

\section{Results}

The total national sample size in the Saudi data set was 35, 279 healthy children and adolescents of which 15554 children from birth to 60 months of age were the subjects of this report. Table 1 presents the prevalence of BMI $>+2$ SDS using the WHO reference (overweight by WHO cutoff), indicating an overall prevalence of 6\% with a peak prevalence of $10.6 \%$ between the ages $12-23$ months, but no significant difference between boys and girls $(p=0.531)$ ). Comparison of the prevalence of BMI $>+2$ SDS (overweight, according to the WHO cutoff) in the age group 24-60 months between the WHO and CDC reference is shown in Table 2 with prevalence of $5 \%$ and $5.8 \%$ respectively, a difference that is not significant $(p=0.100)$. Prevalence values using a lower cut off for BMI for age $>+1$ SDS (equivalent to CDC cutoff for overweight) were $15.7 \%$ and $12.2 \%$ based on the WHO and CDC references respectively (Table 3$)$, indicating a significant difference $(p=0.001)$ but no difference between boys and girls neither in the WHO $(p=0.671)$ nor in the CDC reference $(p=0.977)$. The Fig. 1 shows the prevalence of excess weight at different cutoff levels and age groups using the WHO standards as reference demonstrating variability with cut off and age.

\section{Discussion}

Most studies demonstrating increasing prevalence of overweight involve schoolchildren and adolescents where the problem has been shown to persist in adolescence and in adulthood leading to major health problems. ${ }^{18}$ In addition, it has been shown that overweight preschool children (BMI $>85$ th percentile) were at least 5 times as likely to be overweight at 12 years than those who are not overweight, ${ }^{19}$ and that rapid increases of weight for length in the first 6 and 4 months of life were associated with increased risk of obesity at 3 and 7 years of age respectively. ${ }^{20}$ These reports and others demonstrate the importance of surveillance of overweight infants and young children.

Table 2

Comparative prevalence of BMI $>+2$ SDS by age and sex.

\begin{tabular}{|c|c|c|c|c|c|c|}
\hline \multirow[t]{3}{*}{ Age groups (months) } & \multicolumn{3}{|c|}{ WHO standards } & \multicolumn{3}{|c|}{ CDC reference } \\
\hline & \multicolumn{3}{|c|}{ No. of children (\%) } & \multicolumn{3}{|c|}{ No. of children (\%) } \\
\hline & Boys & Girls & Combined & Boys & Girls & Combined \\
\hline $24-35$ & $696(7.2)$ & $727(6.1)$ & $1423(6.7)$ & $705(6.5)$ & $730(5.9)$ & $1435(6.2)$ \\
\hline $36-47$ & $714(5.2)$ & $784(5.2)$ & $1498(5.2)$ & $718(6.5)$ & $786(6.4)$ & $1504(6.5)$ \\
\hline $48-60$ & $844(3.9)$ & $829(2.5)$ & $1673(3.2)$ & $770(5.5)$ & $766(3.7)$ & $1536(4.6)$ \\
\hline Overall & $2254(5.4)$ & $2340(4.6)$ & $4594(5.0)^{\mathrm{a}}$ & $2193(6.2)$ & $2282(5.3)^{a}$ & $4475(5.8)$ \\
\hline
\end{tabular}

${ }^{a} p=0.100$. 
Table 3

Comparative prevalence of BMI $>+1$ SDS by age and sex.

\begin{tabular}{|c|c|c|c|c|c|c|}
\hline \multirow[t]{3}{*}{ Age groups (months) } & \multicolumn{3}{|c|}{ WHO standards } & \multicolumn{3}{|l|}{ CDC reference } \\
\hline & \multicolumn{3}{|c|}{ No. of children (\%) } & \multicolumn{3}{|c|}{ No. of children (\%) } \\
\hline & Boys & Girls & Combined & Boys & Girls & Combined \\
\hline $24-35$ & $696(18.7)$ & $727(18.4)$ & $1423(18.6)$ & $705(13.5)$ & $730(12.6)$ & $1435(13.1)$ \\
\hline $36-47$ & $714(16.0)$ & $784(16.2)$ & $1498(16.1)$ & $718(13.1)$ & $786(13.1)$ & $1504(13.1)$ \\
\hline $48-60$ & $844(13.0)$ & $829(11.6)$ & $1673(12.3)$ & 770 (11.6) & 766 (12.7) & $1536(12.2)$ \\
\hline Overall & $2254(15.9)^{\mathrm{a}}$ & $2340(15.4)$ & $4594(15.7)^{c}$ & $2193(12.7)^{b}$ & $2282(12.8)^{\mathrm{C}}$ & $4475(12.8)$ \\
\hline
\end{tabular}

${ }^{\mathrm{a}} p=0.671 ;{ }^{\mathrm{b}} p=0.977 ;{ }^{\mathrm{c}} p=0.001$.

The prevalence of overweight in preschool children using the new WHO standards as reference has rarely been reported in nationally representative studies. Recently, the availability of distribution of BMI for age in a national survey of healthy Saudi children and adolescents allowed qualitative comparison with other populations which revealed important differences. ${ }^{21}$ The present report demonstrates high prevalence of BMI $>+2$ SDS (overweight by WHO definition) in Saudi preschool children especially in infants. The effect of feeding practice on prevalence data in this report could not be analyzed because of very early introduction of artificial milk formula to Saudi infants. Our data indicated that $50 \%$ of the infants were started on formula at 1 month, $89.8 \%$ at 6 months, and $98.2 \%$ at 12 months of age. ${ }^{22}$ As a result of overfeeding, this feeding practice may explain at least in part the peak BMI $>+2$ SDS between 12 and 23 months. The prevalence of BMI $>+2$ SDS (overweight by WHO definition) was not significantly different between the WHO and the CDC references. However, when a lower cutoff (BMI $>+1$ SDS) was used, the prevalence of excess weight was significantly higher with the use of WHO (15.7\%) than with the CDC reference (12.2\%), indicating that the effect of the type of reference is not uniform across all levels of cutoffs. In addition, this finding suggests that CDC reference, which is based on a population with increased prevalence of overweight, probably underestimates the prevalence of overweight. By contrast, the WHO standards which are based on healthier population of international background should give better estimate of prevalence of overweight and therefore seem to be the most suitable international reference for the surveillance of overweight in preschool children. In view of the role of excess weight in infants and young children in the development of overweight in older age groups, ${ }^{19,20}$

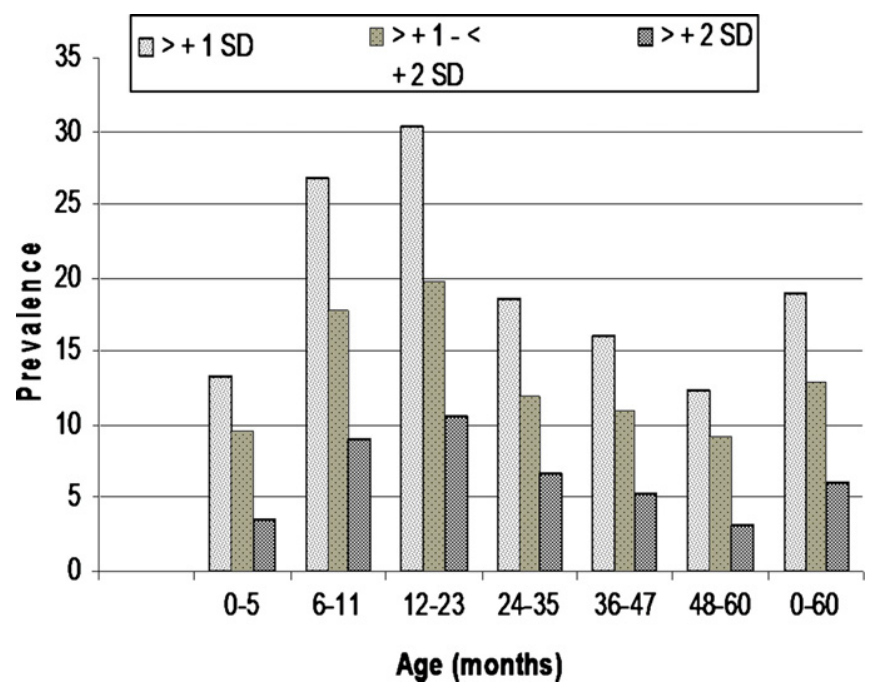

Fig. 1. Prevalence of overweight by age. there is a need for the definition of lower cutoffs for overweight based on the new WHO reference. Although we have not performed comparison with the ITOF reference, others have reported less prevalence of overweight and obesity in comparison with the CDC reference. ${ }^{23}$

Comparison of prevalence values in this study with those of other authors is difficult because of differences in age groups, type of samples, definition of cutoffs, and type of reference used. The report on prevalence of overweight in a population of U S children aged $0-59$ months, ${ }^{24}$ using both the $\mathrm{WHO}^{10}$ and the $\mathrm{CDC}$ reference growth charts ${ }^{25}$ is the most comparable to the present study, indicating a higher prevalence of BMI $>+2$ SDS of $8.3 \%$ compared to $6 \%$ in the present report. The prevalence of BMI $>85$ th percentile (CDC cutoff for overweight) in another US population of children 2-5 years of age using the $\mathrm{CDC}$ reference was reported to be $22.6 \%$ ( 23 for boys and 22.3 for girls) clearly higher than the $12.8 \%$ prevalence in our population but indicating no difference of prevalence between boys and girls. ${ }^{26}$ A similarly high prevalence of excess weight (BMI $>85$ th percentiles) of $26.5 \%$ was reported in children $2-6$ years of age from the Northeast of Brazil. ${ }^{27}$ On the other hand, using the WHO reference, a low prevalence of overweight and obesity of $4.5 \%$ and $1.4 \%$ was reported in 2-5 years old children from South India. 28 Similar prevalence values for overweight and obesity to ours (13.7\% and $5.2 \%$ respectively) have been reported from Nigeria. ${ }^{29}$

In conclusion, the prevalence of BMI $>+2$ SDS (overweight by WHO cutoff) in Saudi infants and young children is intermediately high, calling for preventive measures to prevent further increases described in other countries. The WHO child growth standards, based on an international sample healthier than others, appear to be a more suitable reference for the surveillance of overweight in preschool children. However, this assumption needs confirmation by further studies on the relationship between cutoffs and health outcome.

\section{Conflict of interest}

There no conflict of interest in this work.

\section{Acknowledgements}

This study was funded by King Abdul-Aziz City for Science and Technology in Riyadh, Saudi Arabia (grant no: AR-20-63).

MIE conceived, directed the study and drafted the manuscript. PJF performed and supervised the statistical analysis.

ASAH participated in the design of the study and supervision of data collection.

AAAS participated in the design of the study and supervision of data collection.

AAAO participated in the design of the study and supervision of data collection.

M A Q participated in the design of the study and supervision of data collection.

$\mathrm{T} \mathrm{K}$ helped in the statistical analysis.

All authors have approved the final manuscript. 


\section{References}

1. Ogden $\mathrm{Cl}$, Flegal KM, Carroll MD, Johnson CL. Prevalence and trends in overweight and obesity among children and adolescents, 1999-2000. JAMA 2002;288: $1728-32$

2. Reilly JJ. Tackling the obesity epidemic: new approaches. Arch Dis Child 2006;91:724-6.

3. Barbiero SM, Pellanda LC, Cesa CC, Campagnolo P, Beltrami E, Abrantes CC. Overweight, obesity and other risk factors for IHD in Brazilian schoolchildren. Public Health Nutr 2008;23:1-6.

4. Malik M, Bakir A. Prevalence of overweight and obesity among children in the United Arab Emirates. Obes Rev 2007;8:15-20.

5. Al-Hazzaa HM. Prevalence and trend in obesity among schoolchildren in Central Saudi Arabia between 1988 and 2005. Saudi Med J 2007;28: 1569-74.

6. Raj M, Sandaram KR, Paul M, Deepa AS, Kumar RK. Obesity in Indian children: time trends and relationship with hypertension. Natl Med J India 2007;20: 288-93.

7. Raja' a YA, Bin Mohanna MA. Overweight and obesity among schoolchildren in Sana'a City, Yemen. Ann Nutr Metab 2003;49:342-5.

8. Wang Y, Lobstein T. Worldwide trends in childhood overweight and obesity. Int J Pediatr Obes 2006;1:11-25.

9. Cole TJ, Bellizzi MC, Flegal KM, Dietz WH. Establishing a standard definition for child overweight and obesity worldwide: international survey. $\mathrm{Br}$ Med J 2000;320:1240-6.

10. Onis Mercedes de, et al. The WHO child growth standard: methods and development. Geneva, Switzerland: Department of Nutrition for Health and Development. WHO; 2006

11. El Mouzan MI, Al Herbish AS, Al Salloum AA, Al-Qurachi M, Al-Omer Ahmad. The growth charts for Saudi children and adolescents. Saudi Med J 2007;28(10):477-90.

12. Waterlow JC, Buzina R, Keller W, et al. The presentation and use of height and weight data for comparing the nutritional status of groups of children under the age of ten years, vol. 55. Geneva: WHO Bull; 1977. p. 489-98.

13. Cole TJ, Green PJ. Smoothing reference percentile: the LMS method and penalized likelihood. Stat Med 1992;11:1305-19.

14. Cole TJ, Freeman JV, Preece MA. British 1990 growth reference centiles for weight, height, body mass index and head circumference fitted by maximum penalized likelihood. Stat Med 1998;17:407-29.
15. Rigby RA, Stasinopoulos DM. Generalized additive models for location, scale and shape. Appl Stat 2005;64:507-54.

16. http://www.who.int/childgrowth/software/en/.

17. Whitaker RC, Wright JA, Pepe MS, Seidel KD, Dietz WH. Predicting obesity in young adulthood from childhood and parental obesity. $N$ Engl J Med 1997;337:869-73.

18. Guo SS, Chumlea WC. Tracking of body mass index in children in relation to overweight in adulthood. Am J Clin Nutr 1999;70(Suppl):145S-8S.

19. Nader PR, O’Brien M, Houts R, Bradley R, Belsky J, Crosnoe R, et al. Identifying risk for obesity in early childhood. Pediatrics 2006;118:594-601.

20. Taveras EM, Rifas-Shiman SL, Belfort MB, Kleinman KP, Oken E, Gilman MW. Weight status in the first 6 months of life and obesity at 3 years of age. Pediatrics 2009;123:1177-83.

21. Al Herbish A, El Mouzan M, Al Salloum A, Qurachi M, Al Omer A, Foster P, et al. Body mass index for Saudi Arabian children and adolescent: a national reference with comparison to international charts. Ann Saudi Med 2009;29(5):342-7.

22. El Mouzan MI, Al Omer A, Al Salloum A, Al Herbish A, Qurachi M. Trends in infant nutrition in Saudi Arabia: compliance with WHO recommendations. Ann Saudi Med 2009;29:20-3.

23. Edwards J, Evans J, Brown AD. Using routine growth data to determine overweight and obesity prevalence estimates in preschool children in the Capital Health Region of Alberta. Can J Public Health 2008;99:91-4.

24. Mei Z, Ogden CL, Flegal KM, Grummer-Straun LM. Comparison of the prevalence of Shortness, Underweight, and Overweight among US children Aged 0 to 59 months by using the CDC 2000 and the WHO 2006 Growth Charts. J Pediatr; 2008:622-8.

25. Kuczmarski RJ, Ogden CL, Guo SS, Grummer-Straun LM, Flegal KM, Mei Z, et al. The 2000 CDC growth charts for the United States: methods and development. National Center for Health Statistics. Vital Health Stat 2002;11(246).

26. Hedley AA, Ogden CL, Johnson CL, Carroll MD, Curtin LR, Flegal KM. Prevalence of overweight and obesity among US children, adolescents and adults, 19992002. JAMA 2004;291:2847-50.

27. Barreto AC, Brasil Ldo M, Maranhao Hde S. Prevalence of excess weight in preschoolers of the Northeast of Brazil. Rev Assoc Med Bras 2007;53:311-6.

28. Kumar HN, Mohannan P, Kotian S, Sajjan BS, Kumar SG. Prevalence of overweight and obesity among preschool children in semi urban South India. Indian Pediatr 2008;45:497-9.

29. Senbanjo IO, Adejuygbe EA. Prevalence of overweight and obesity in Nigerian preschool children. Nutr Health 2007;18:391-9. 